\title{
Ferromagnetic resonance and random magnetic anisotropy in nanocrystalline $\mathrm{Fe}-\mathrm{Zr}-\mathrm{N}$ films
}

\author{
Elena Sheftel ${ }^{1}$, Eugene Harin ${ }^{1, *}$, Valentin Tedzhetov ${ }^{1}$, and Yuri Koksharov ${ }^{2}$ \\ ${ }^{1}$ A.A. Baikov Institute of Metallurgy and Materials Science RAS, Moscow, Russia \\ ${ }^{2}$ M.V. Lomonosov Moscow State University, Moscow, Russia
}

\begin{abstract}
The effective magnetic anisotropy of the ferromagnetic nanocrystalline Fe-Zr-N films prepared by magnetron sputtering under different conditions has been determined by both correlation magnetometry and ferromagnetic resonance methods. The effective magnetic anisotropy values obtained by the two methods are compared and the origin of the values is discussed.
\end{abstract}

\section{Introduction}

At present, efforts are being made to design soft magnetic nanocrystalline films intended for devices operating at high frequencies $[1,2]$. Thus, it is of interest to find correlations between parameters describing static magnetic properties (magnetic anisotropy and exchange interaction) and high frequency properties.

The random magnetic anisotropy model [3] is widely used to describe the hysteresis for nanocrystalline ferromagnets. In accordance with the model, the magnetization of individual grains is randomly oriented and can be described by an autocorrelation function for the magnetization. The magnetic autocorrelation length $\left(R_{L}\right)$ is an important parameter of the function and is a typical magnetic microstructure radius corresponding to relatively uniform magnetization (a stochastic magnetic domain). The model is valid when $R_{L}>R_{c}$, where $R_{c}$ is a grain radius, and grains are exchange coupled. In this case, magnetic hysteresis is determined by magnetic structure parameters, such as $R_{L}$, the effective magnetic anisotropy $\left\langle K_{e f f}>\right.$ at $R_{L}$ scale, and the effective magnetic anisotropy $K_{\text {eff }}$ at $R_{c}$ scale. The correlation magnetometry method [4] allows one to determine these magnitudes using a magnetization curve.

In this case, not only the correlation magnetometry, but also ferromagnetic resonance (FMR) method allows one to determine the effective magnetic anisotropy.

The correspondence of two effective magnetic anisotropy values determined by the two methods, namely, by correlation magnetometry (static magnetic properties) and FMR methods, will allow us to estimate the high frequency properties using the data on measured static magnetic properties. This is of substantial interest since the measurement of high frequency magnetic permeability is difficult because of strict requirements for the dimensions and shape of films, kind of substrate and its thickness, and other experimental difficulties.

Among soft magnetic films studied in the recent years, the nanocrystalline Fe-Zr-N films are of substantial interest for investigators. This is related, on the one hand, to the possibility to prepare such films in amorphous and nanocrystalline states, in particular by magnetron sputtering, and, on the other hand, to the prospect to prepare such films with the unique static and high frequency soft magnetic properties $[5,6]$.

The aim of the present study is to measure the effective magnetic anisotropy values for the Fe-Zr-N films using correlation magnetometry and FMR and to analyze the origin of the obtained values.

\section{Experimental}

The ferromagnetic nanocrystalline Fe-Zr-N films of 0.3-1.7 $\mu \mathrm{m}$ in thickness were prepared by magnetron sputtering of the $\mathrm{Fe}$ and $\mathrm{Fe}-\mathrm{Zr}$ targets containing 2.4 and 5.3 wt.\% Zr. The films were deposited on the glass substrates. The $\mathrm{N}_{2}$ content in the $\mathrm{Ar}+\mathrm{N}_{2}$ gas mixture was 0,5 , and $15 \%$; the gas mixture pressure was 0.13-0.2 Pa. The preparation conditions are described in detail in $[6,7]$.

The structure of the films (phase composition, lattice parameter, and $R_{c}$ grain radius) was studied by X-ray diffraction analysis [6]. The chemical composition of the as-sputtered films was determined by glow-discharge optical emission spectroscopy [8].

The saturation magnetization $\left(M_{s}\right)$ was determined in magnetic fields up to $16 \mathrm{kOe}$ using a vibrating sample magnetometer and Akulov's law of approach to saturation magnetization; depending on the preparation conditions of the films, their saturation magnetization was ranged within 1300-1700 $\mathrm{G}(1.6-2.1 \mathrm{~T})$. The magnetic structure parameters $\left(K_{\text {eff }},\left\langle K_{\text {eff }}>\right.\right.$, and $\left.R_{L}\right)$ were determined by correlation magnetometry [4].

The dependencies of FMR spectrum on applied dc magnetic fields up to $6 \mathrm{kOe}$ were measured at the frequency $f=9.54 \mathrm{GHz}$ using a Varian E-4 spectrometer.

\footnotetext{
Corresponding author: harin-eugene@ya.ru
} 
All measurements were performed at room temperature.

\section{Results and discussion}

\subsection{Phase composition and structure}

According to X-ray diffraction data, the films under study contain $\alpha-\mathrm{Fe}, \mathrm{Fe}_{4} \mathrm{~N}, \mathrm{Fe}_{3} \mathrm{~N}, \mathrm{Fe}_{2} \mathrm{~N}$ phases coexisting in various proportions; depending on the composition and the preparation conditions, the grain size of the phases is 2-50 nm (Table 1).

Table 1. Chemical composition and structure of the films under study

\begin{tabular}{|c|c|c|c|}
\hline $\begin{array}{l}\text { Film } \\
\text { No. }\end{array}$ & $\begin{array}{c}\text { Chemical } \\
\text { composition, } \\
\text { at. } \%\end{array}$ & $\begin{array}{c}\text { Phase } \\
\text { composition, } \\
\text { vol. } \%\end{array}$ & $\begin{array}{c}\alpha \text {-Fe grain } \\
\text { size }\left(2 R_{c}\right), \\
\text { nm }\end{array}$ \\
\hline 1 & $\mathrm{Fe}$ & $\alpha-\mathrm{Fe}$ & $39 \pm 11$ \\
\hline 2 & $\mathrm{Fe}_{90} \mathrm{~N}_{10}$ & $\begin{array}{c}\alpha-\mathrm{Fe}(\mathrm{N}) \\
+5 \% \mathrm{Fe}_{2} \mathrm{~N}\end{array}$ & 15 \\
\hline 3 & $\mathrm{Fe}_{95} \mathrm{Zr}_{5}$ & $\alpha-\mathrm{Fe}(\mathrm{Zr})$ & $34 \pm 3$ \\
\hline 4 & $\mathrm{Fe}_{85} \mathrm{Zr}_{5} \mathrm{~N}_{10}$ & $\begin{array}{l}\alpha-\mathrm{Fe}(\mathrm{N}, \mathrm{Zr}) \\
+7 \% \mathrm{Fe}_{2} \mathrm{~N}\end{array}$ & $11 \pm 1$ \\
\hline 5 & $\mathrm{Fe}_{86} \mathrm{Zr}_{4.3} \mathrm{~N}_{6.7} \mathrm{O}_{2.9}$ & $\begin{array}{c}\alpha-\mathrm{Fe} \\
+42 \% \mathrm{Fe}_{4} \mathrm{~N}\end{array}$ & $4 \pm 2$ \\
\hline 6 & $\mathrm{Fe}_{87.3} \mathrm{Zr}_{2.4} \mathrm{~N}_{7.4} \mathrm{O}_{2.9}$ & $\begin{array}{c}\alpha-\mathrm{Fe} \\
+64 \% \mathrm{Fe}_{4} \mathrm{~N} \\
+5 \% \mathrm{Fe}_{3} \mathrm{~N}\end{array}$ & $7 \pm 3$ \\
\hline 7 & $\mathrm{Fe}_{90.4} \mathrm{Zr}_{2.9} \mathrm{~N}_{4.7} \mathrm{O}_{2}$ & $\alpha-\mathrm{Fe}$ & $17 \pm 3$ \\
\hline 8 & $\mathrm{Fe}_{75.8} \mathrm{Zr}_{8.7} \mathrm{~N}_{6.8} \mathrm{O}_{8.7}$ & $\alpha-\mathrm{Fe}$ & $5 \pm 1$ \\
\hline 9 & $\mathrm{Fe}_{82.5} \mathrm{Zr}_{3.1} \mathrm{~N}_{6.4} \mathrm{O}_{8}$ & $\begin{array}{c}\alpha-\mathrm{Fe} \\
+42 \% \mathrm{Fe}_{4} \mathrm{~N}\end{array}$ & $10 \pm 2$ \\
\hline 10 & $\mathrm{Fe}$ & $\alpha-\mathrm{Fe}$ & 46 \\
\hline
\end{tabular}

\subsection{FMR study}

Differential microwave absorption spectra for the films under study were measured in dc magnetic fields applied in the film plane (Fig. 1). The in-plane FMR condition is determined by Kittel's law [9]

$$
(f / \gamma)^{2}=\left(H_{r e s}+4 \pi M_{s}\right)\left(H_{r e s}+2 K / M_{s}\right),
$$

where $\gamma=2.9 \mathrm{MHz} / \mathrm{Oe}$ is the gyromagnetic ratio, $K$ is the FMR-driving magnetic anisotropy, and $H_{r e s}$ is the resonant field. The $H_{\text {res }}$ values were determined as the applied dc field values corresponding to the midpoint between differential peaks using the in-plane FMR spectra ("peak-to-peak" method, Fig. 1, Table 2). After that, the $K$ values were determined by Eq. (1).

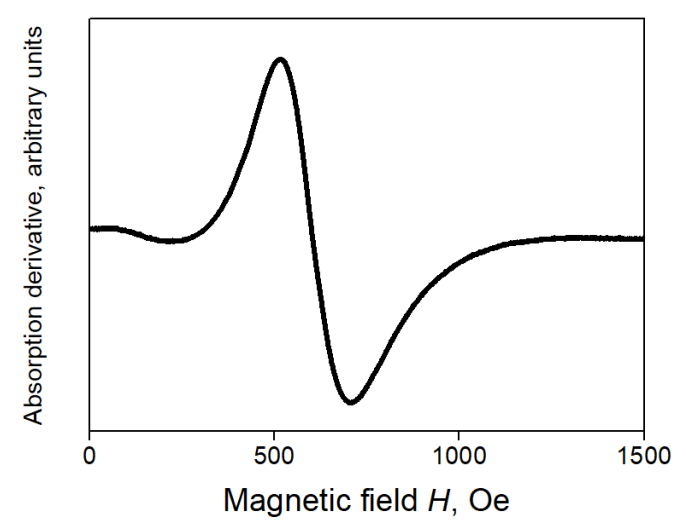

Fig. 1. In-the-film-plane FMR spectrum of the film No. 2.

\subsection{Correlation magnetometry study}

In terms of correlation magnetometry theory, the magnetization curves measured in high magnetic fields were recalculated for the magnetization dispersion $d_{m}=\left(M_{s}-M\right) / M_{s}$ and plotted on log-log scale. This allowed us to find two laws of approach to saturation magnetization (Fig. 2): $d_{m}=(1 / 2)\left(D H_{a}\right)^{2} /\left(H_{R}{ }^{3 / 2} H^{1 / 2}\right)$ in fields $H<H_{R}$ and $d_{m}=(1 / 2)\left(D H_{a} / H\right)^{2}$ in fields $H>H_{R}$ ( $D=1 / 15^{1 / 2}$ for the uniaxial anisotropy), which were used to determine the local magnetic anisotropy $\left(K_{\text {eff }}=H_{a} M_{s} / 2\right)$ and the exchange field $\left(H_{R}\right.$, Table 2$)$.

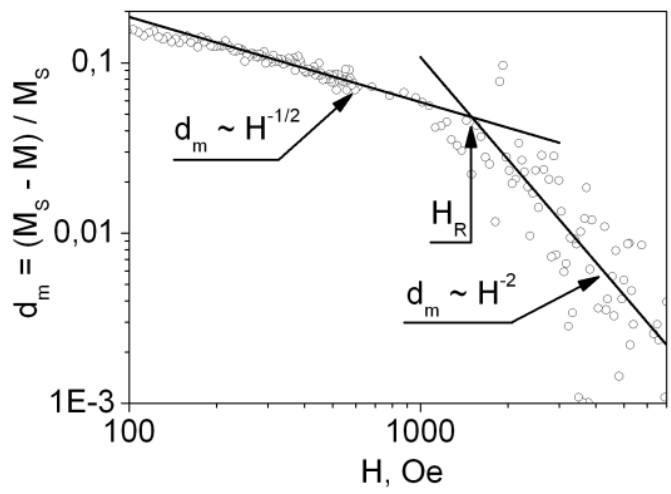

Fig. 2. The magnetization dispersion of the film No. 2. Solid lines are described in the text.

When such a material is under magnetization process, three phenomena occur simultaneously, which, as the applied magnetic field increases, become dominant in the following sequence: (1) stochastic domain magnetization rotation within $2 R_{L}$, (2) progressive decrease in the stochastic domain size down to $2 R_{c}$ grain scale, and (3) in fields $H>H_{R}$, magnetization rotation within individual grains $\left(K_{\text {eff }}\right.$ within $2 R_{c}$ ). The magnetic structure of the films under study was discussed in detail in our previous works [6,7].

According to [4], the dependence of effective magnetic anisotropy of nanocrystalline ferromagnets on the applied dc magnetic field can be described by several different functions. In particular, at $H>H_{R}$, the effective magnetic anisotropy [4] is constant and equal to the $K_{\text {eff }}$ 
magnitude within a ferromagnetic grain. At $H<H_{R}$, the effective magnetic anisotropy equals

$$
K_{H}=K_{e f f}\left(R_{c} / R_{H}\right)^{3 / 2},
$$

where $R_{H}=\left(2 A / M_{S} H\right)^{1 / 2}$ is the magnetic autocorrelation radius in $H$ field and $A$ is the exchange stiffness.

Table 2. Magnetic properties of the films under study

\begin{tabular}{|c|c|c|c|c|c|c|}
\hline$\underset{\dot{\theta}}{\dot{B}}$ & $\begin{array}{c}\text { Chemical } \\
\text { compo- } \\
\text { sition, } \\
\text { at.\% }\end{array}$ & $\begin{array}{c}M_{s}, \\
\mathbf{G}\end{array}$ & $\begin{array}{c}H_{R}, \\
\text { Oe }\end{array}$ & $\begin{array}{l}H_{\text {ress }}, \\
\text { Oe }\end{array}$ & $\begin{array}{c}K_{e f f} \\
10^{5} \\
\operatorname{erg} / \mathrm{cm}^{3}\end{array}$ & $\begin{array}{c}K, \\
10^{5} \\
\text { erg/cm }\end{array}$ \\
\hline 1 & $\mathrm{Fe}$ & $\begin{array}{c}1683 \\
\pm 8\end{array}$ & $\begin{array}{l}1700 \\
\pm 700\end{array}$ & $\begin{array}{c}1690 \\
\pm 30\end{array}$ & $\begin{array}{l}10.1 \\
\pm 3.4\end{array}$ & $\begin{array}{l}10.2 \\
\pm 0.4\end{array}$ \\
\hline 2 & $\mathrm{Fe}_{90} \mathrm{~N}_{10}$ & $\begin{array}{c}1332 \\
\pm 20\end{array}$ & $\begin{array}{l}1500 \\
\pm 400\end{array}$ & $\begin{array}{l}830 \\
\pm 30\end{array}$ & $\begin{array}{c}12 \\
\pm 2.9\end{array}$ & $\begin{array}{c}1.4 \\
\pm 0.3\end{array}$ \\
\hline 3 & $\mathrm{Fe}_{95} \mathrm{Zr}_{5}$ & $\begin{array}{c}1598 \\
\pm 9\end{array}$ & $\begin{array}{l}280 \\
\pm 40\end{array}$ & $\begin{array}{c}1840 \\
\pm 30\end{array}$ & $\begin{array}{c}6.4 \\
\pm 0.8\end{array}$ & $\begin{array}{l}10.8 \\
\pm 0.3\end{array}$ \\
\hline 4 & $\begin{array}{c}\mathrm{Fe}_{85} \mathrm{Zr}_{5} \\
\mathrm{~N}_{10}\end{array}$ & $\begin{array}{c}1310 \\
\pm 7\end{array}$ & $\begin{array}{l}800 \\
\pm 50\end{array}$ & $\begin{array}{c}1920 \\
\pm 30\end{array}$ & $\begin{array}{l}10.5 \\
\pm 0.7\end{array}$ & $\begin{array}{c}8.7 \\
\pm 0.3\end{array}$ \\
\hline 5 & $\begin{array}{c}\mathrm{Fe}_{86} \mathrm{Zr}_{4.3} \\
\mathrm{~N}_{6.7} \mathrm{O}_{2.9}\end{array}$ & $\begin{array}{c}1439 \\
\pm 5\end{array}$ & 21389 & 643 & 7.2 & $\begin{array}{c}0.47 \\
\pm 0.01\end{array}$ \\
\hline 6 & $\begin{array}{c}\mathrm{Fe}_{87.3} \mathrm{Zr}_{2.4} \\
\mathrm{~N}_{7.4} \mathrm{O}_{2.9}\end{array}$ & $\begin{array}{l}1318 \\
\pm 0.5\end{array}$ & $\begin{array}{c}13000 \\
\pm 700\end{array}$ & $\begin{array}{c}596 \\
\pm 1\end{array}$ & $\begin{array}{c}4.1 \\
\pm 0.1\end{array}$ & $\begin{array}{c}0.23 \\
\pm 0.01\end{array}$ \\
\hline 7 & $\begin{array}{c}\mathrm{Fe}_{90.4} \mathrm{Zr}_{2.9} \\
\mathrm{~N}_{4.7} \mathrm{O}_{2}\end{array}$ & $\begin{array}{c}1720 \\
\pm 12\end{array}$ & 25022 & $\begin{array}{c}563 \\
\pm 1\end{array}$ & 8.7 & $\begin{array}{c}0.64 \\
\pm 0.05\end{array}$ \\
\hline 8 & $\begin{array}{c}\mathrm{Fe}_{75.8} \mathrm{Zr}_{8.7} \\
\mathrm{~N}_{6.8} \mathrm{O}_{8.7} \\
\end{array}$ & $\begin{array}{c}1371 \\
\pm 1 \\
\end{array}$ & $\begin{array}{r}16000 \\
\pm 2600 \\
\end{array}$ & $\begin{array}{c}695 \\
\pm 1 \\
\end{array}$ & $\begin{array}{c}4.3 \\
\pm 0.5 \\
\end{array}$ & $\begin{array}{c}0.62 \\
\pm 0.01 \\
\end{array}$ \\
\hline 9 & $\begin{array}{c}\mathrm{Fe}_{82.5} \mathrm{Zr}_{3.1} \\
\mathrm{~N}_{6.4} \mathrm{O}_{8}\end{array}$ & $\begin{array}{c}1404 \\
\pm 9\end{array}$ & 25120 & $\begin{array}{c}627 \\
\pm 1\end{array}$ & $\begin{array}{c}7.2 \\
\pm 0.1\end{array}$ & $\begin{array}{c}0.24 \\
\pm 0.03\end{array}$ \\
\hline 10 & $\mathrm{Fe}$ & 1414 & $\begin{array}{l}22000 \\
\pm 1300\end{array}$ & $\begin{array}{l}275 \\
\pm 15\end{array}$ & $\begin{array}{c}6.7 \\
\pm 0.7\end{array}$ & $\begin{array}{c}2.3 \\
\pm 0.11\end{array}$ \\
\hline
\end{tabular}

\subsection{Comparison of magnetic anisotropy from FMR and correlation magnetometry}

In accordance with the resonant field value $\left(H_{\text {res }}\right)$ from Eq. (1), the films under study can be divided into two groups: $H_{\text {res }} \geq H_{R}$ (group I, 3 films in Fig. 3 ) and $H_{\text {res }}<H_{R}$ (group II, 7 films in Fig. 3).

In accordance with the aforementioned considerations, the magnetic anisotropy determined from the resonant condition is $K \approx K_{\text {eff }}$ for group I ( 3 films in Fig. 4) and $K<K_{\text {eff }}$ for group II (7 films in Fig. 4).

In the case of group II, the $K_{H}$ and $K$ magnitudes correlate adequately. In particular, for film No. 2 (Figs. 1 and 2, Table 2), the resonant field is $H<H_{R}$. In accordance with the aforementioned considerations, for

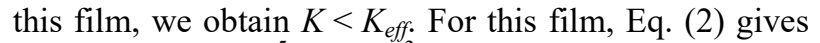
$K_{H}=(7.4 \pm 4.3) \cdot 10^{5} \mathrm{erg} / \mathrm{cm}^{3}$, which agrees adequately with $K=(1.4 \pm 0.3) \cdot 10^{5} \mathrm{erg} / \mathrm{cm}^{3}$.

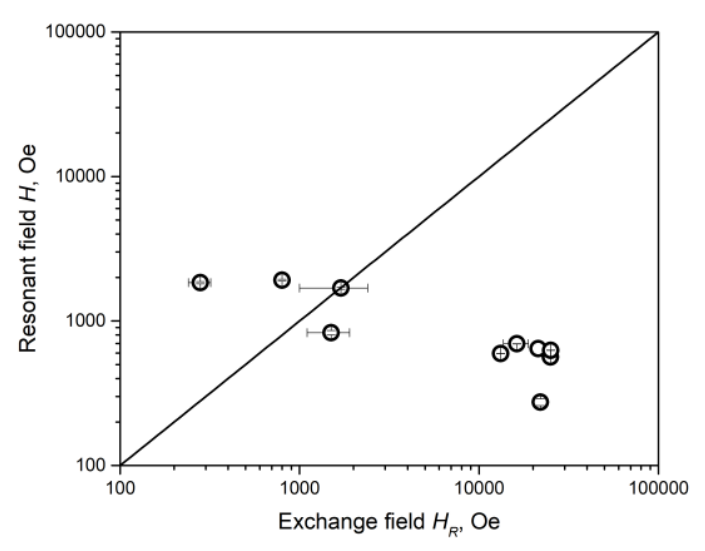

Fig. 3. Comparison of the resonant $\left(H_{r e s}\right)$ and exchange $\left(H_{R}\right)$ fields for the films under study. Solid line corresponds to $H=H_{R}$.

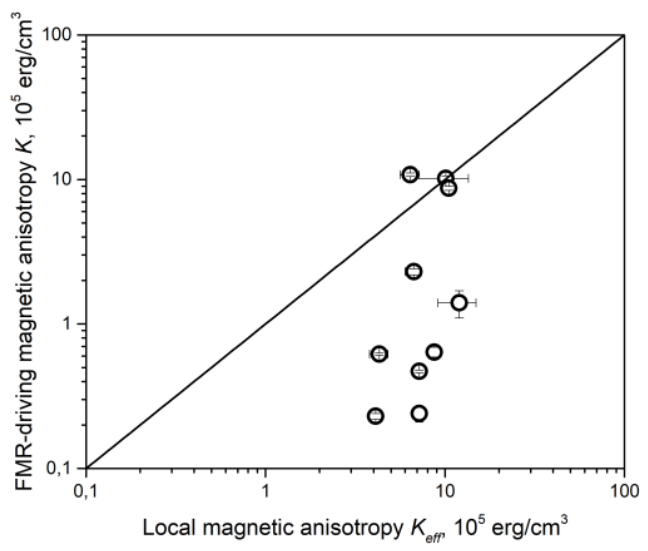

Fig. 4. Comparison of the FMR-driving magnetic anisotropy $(K)$ and the local magnetic anisotropy $\left(K_{\text {eff }}\right)$ for the films under study. Solid line corresponds to $K=K_{\text {eff. }}$.

\section{Conclusions}

The effective magnetic anisotropy of the ferromagnetic nanocrystalline $\mathrm{Fe}-\mathrm{Zr}-\mathrm{N}$ films prepared by magnetron sputtering under different conditions has been measured by correlation magnetometry and FMR methods.

For some films, the resonant microwave power absorption takes place when the applied dc magnetic field is lower than the exchange field $\left(H_{\text {res }}<H_{R}\right)$. It means, in this external magnetic field $\left(H_{\text {res }}<H_{R}\right)$, the resonance condition is determined by the magnetic anisotropy within a stochastic domain, which exists in this applied dc magnetic field, but not the magnetic anisotropy $K_{\text {eff }}$ within a grain.

Future investigations will be related to the estimation of the dependence of the resonant field value on the frequency of the ferromagnetic resonance, which will allow us to obtain the dependence of effective magnetic anisotropy of stochastic domain on the applied magnetic field for a material with the stochastic domain structure.

This study was supported by RFBR (project No. 15-08-02831a). 


\section{References}

1. S.S. Kalarickal, P. Krivosik, M. Wu, C.E. Patton, M.L. Schneider et al. J. Appl. Phys. 99, 093909 (2006)

2. H.-S. Song, K.-D. Lee, Ch.-Y. You, B.-G. Park, J.-I. Hong, J. Magn. Magn. Mat. 406, 129 (2016)

3. G. Herzer, Acta Materialia 61, 718 (2013)

4. R.S. Iskhakov, S.V. Komogortsev, Phys. of Metals and Metallography 112, 666 (2011)

5. R.S. Iskhakov, M.M. Brushtunov, A.G. Narmonev, et al. Phys. Metals and Metallography 79, Iss. 5, 122 (1995)

6. E.N. Sheftel, E.V. Harin, V.A. Tedzhetov, et al. Physica B 494, 13 (2016)

7. E.V. Harin, E.N. Sheftel, Phys. Metals and Metallography 116, 753 (2015)

8. Ph.V. Kiryukhantsev-Korneev, Prot. Met. Phys. Chem. 48, 585 (2012)

9. F. Gerhardter, Y. Li, K. Baberschke, Phys. Rev. B 47, 11204 (1993) 